\title{
Characteristics of female sex workers and their HIV/AIDS/STI knowledge, attitudes and behaviour in semi-urban areas in South Africa
}

\author{
K Peltzer, Human Sciences Research Council \& University of KwaZulu-Natal \\ P Seoka, Health Behaviour Research Unit \\ $S$ Raphala, Health Behaviour Research Unit
}

\section{Abstract}

The aim of this study was to investigate characteristics of female sex workers and their HIV/AIDS/STI knowledge, attitudes and behaviour in semi-urban areas in South Africa. The sample included 70 female sex workers from the Tzaneen and Phalaborwa area in the Limpopo Province. A modified form of snowball sampling known as "targeted" sampling was used for identifying female sex workers. Results showed an inadequate knowledge of HIV prevention methods and some incorrect beliefs about AIDS transmission. Most sex workers reported condom use with their last sex client, inconsistent condom use with paying partners, and had poor condom use with regular partners. One third were drinking alcohol daily, one quarter had had voluntary HIV tests, and three quarters had been exposed to HIV interventions. Findings are discussed and implications for HIV interventions outlined.

\section{Introduction}

In a survey amongst 145 female workers at truck-stops in the Natal Midlands conducted in 1996, an HIV prevalence of $50.3 \%$ has been reported. The clients of sex workers also need to be the focus of interventions; a study of 213 long distance truck-drivers passing through the Natal Midlands indicated that $27 \%$ had a Sexually Transmitted Infection (STI) at some time; $18 \%$ reported swollen glands; $25 \%$ have sex during an infection; $71 \%$ never use condoms and $35 \%$ have more than one partner (Abdool Karim \& AbdoolKarim, 2000: 3). Among commercial sex workers in Johannesburg Rees, Beksinska, Dickson-Tetteh, Ballard and Htun (2000: 284 ) found that $45 \%$ of the women were found to be HIV positive. Positive HIV status was significantly associated with less condom use and women using condoms less than $50 \%$ of the time were more likely to be HIV positive than those using them $50-100 \%$ of the time. The number of clients seen daily was also found to be associated with HIV status, with $54 \%$ of those seeing five clients or more a day being HIV positive compared to $41 \%$ of those with 1-4 partners a day. It has been recognized that in populations with high numbers of sexual contacts, high HIV and STI rates and low condom use play a key role in the transmission of HIV (Rees et al., 2000: 283). Leggett (2002: 103) found in a sample of 249 sex workers from three major cities in South Africa that over $66 \%$ of black sex workers were HIV posi- tive, compared to $18 \%$ of whites and $17 \%$ of coloureds. Mzaidume, Campbell and Williams (2000: 23f.) note that seven out of ten sex workers in Southern Africa are HIVpositive, and that these women face multiple layers of disempowerment such as being in a fiercely hierarchical and male-dominated community, living in conditions of poverty, and working in what they describe as highly stigmatised profession, in a country where their profession receives no legal recognition, and where there is no formal recognition of their rights to work related health and safety. Varga (2001: 355) found among commercial sex workers in Durban that two-thirds $(67.3 \%)$ would not forego condoms for extra payment, and $11.9 \%$ would agree to unprotected sex if the client looked clean and respectable.

Gysels, Pool and Nnalusiba (2002: 179) investigated how women in a trading town on the trans-Africa highway in southwest Uganda became involved in commercial sex work, which factors contribute to their economic success or lack of success, and what effect life trajectories and economic success have on negotiating power and risk behaviour. The women were found to share similar disadvantaged backgrounds and this has played a role in their move into commercial sex. They had divergent experiences, however, in their utilisation of opportunities and in the level of success they achieved. They had developed different life styles and a variety of ways of dealing with sexual relationships. Three groups of women were identified: (1) women who 
work in the back-street bars, have no capital of their own and are almost entirely dependent on selling sex for their livelihood; (2) waitresses in the bars along the main road who engage in a more institutionalised kind of commercial sex, often mediated by middlemen and (3) the more successful entrepreneurs who earn money from their own bars as well as from commercial sex. The three groups had different risk profiles. Due partly to their financial independence from men, women in the iatter group had taken control of sexual relationships and could negotiate good sexual deals for themselves, both financially and in terms of safe sex. The poorer women were more vulnerable and less able to negotiate safer sex. A disadvantaged background and restricted access to economic resources were the major reasons for women gravitating to commercial sex work. Pickering, Okongo, Nnalusiba, Bwanika and Whitworth (1997: 199) studied daily records of prostitutes for 6 months of all their sexual contacts including the occupation and place of residence of each client and the price paid in Uganda. Three classes of women were identified: (1) 'highclass' women who charged a mean price of over US $\$ 4 /$ - per contact. The majority of their clients were from large urban areas of Uganda, or neighbouring countries, mostly truckdrivers or their mates; (2) 'low-class' women, charging an average of US \$0.4 per contact, who were patronized predominantly by men resident in the town who were unskilled casual workers; and (3) women falling into an intermediate category in terms of price and the residence of their clients. Outwater, Nkya, Lwihula, O'Connor, Leshabari (2000: 46) found on the basis of ethnographic studies that commercial sex workers and other high-risk women in Tanzania had different categories of partners, ranging from single-time contacts to long and enduring relationships. These women often used condoms for the single-time contact. However, since the HIV/AIDS epidemic, casual partners had decreased in number. These days, most of their sexual contacts occured within long-term partnerships, and within these relationships, condom use was rare.

Pickering, Quigley, Hayes, Todd and Wilkins (1993: 1093) investigated the factors that influence condom use among prostitutes and their clients in The Gambia and found that condom use varied according to type of partner (from $84 \%$ with clients to only $4 \%$ with regular partners), location (from $91 \%$ in high-class bars to $59 \%$ in rural markets), decreased from $91 \%$ with the first client of the evening to $37 \%$ with the tenth client, and from $75 \%$ with clients paying higher charges to $52 \%$ with those paying lower charges. Condom use was not related to the socio-demographic characteristics of the prostitutes. Varga (1997: 74) ivestigated barriers to condom use among commercial sex workers in Durban and found considerable contrast between factors influencing condom use in professional versus private sex situations. With clients, practical issues such as financial strain were the major obstacles to condom use. With personal sex partners, sex workers avoided condoms due to their negative symbolism.

Commercial sex workers have been studied in South Africa in major urban centres, such as Johannesburg (Wojcicki \& Malala, 2001: 99) and Durban (Varga, 1997: 74) but little is known about female sex workers in rural or semi-urban areas in South Africa, which promted the study.

\section{Methods}

\section{Design}

The study used a cross-sectional descriptive design to interview mobile sex workers in their work setting at different meeting points.

\section{Sample and procedure}

The sample included 70 female sex workers from the Tzaneen and Phalaborwa area in the Limpopo Province. A modified form of snowball sampling known as "targeted" sampling was used for identifying female sex workers (Family Health International, 2000: 65-9). Sex workers were approached for participation in the study at their different working sites by the second and third author. Three opted for not participating in the study. Questionnaires were all interview-administered in Northern Sotho or Tsonga at a private place in or around the participant's work area. Informed consent was obtained. The purpose of the survey was explained to the respondent, including the risks and benefits, as well as the measures to ensure confidentiality. To ensure confidentiality, no identifiers were recorded on the respondent questionnaire. Permission was sought from local authorities and obtained from the University of the North ethics committee. Participants were provided with refreshments and a small honorarium of 20 Rand (2.5 US \$) for completing the interview.

\section{Measure}

The questionnaire used was developed by Family Health International (2000) using standardized indicators on HIV/ AIDS/STD behavioural surveillance surveys (BSS) for use with female sex workers. The questionnaire included the following sections: (0) Questionnaire identification data (6 items), (1) Background characteristics (13 items), (2) Marriage, family, work ( 9 items), (3) Sexual history: numbers and types of partners (3 items), (4) Sexual history: paying clients ( 6 items), (5) Sexual history: non-paying partners $(6$ items), (6) Male and female condoms (7 items), (7) STIs (5 items), (9) Knowledge, opinions, and attitudes towards HIV/ AIDS (18 items), and (10) Exposure to prevention ( 3 items) (Family Health International, 2000).

The questionnaire was pilot tested on 5 sex workers and after 3 weeks re-administered. Test-retest reliability of .78 was found.

From the 18 items on knowledge, opinions, and attitudes towards HIV/AIDS two subscales were created: a 9-item Knowledge on HIV/AIDS Scale and a 6-item Stigmatization Towards HIV/AIDS Index. The Knowledge on HIV/ AIDS scale yielded a Cronbach alpha of .73 and the splithalf reliability coefficient of .70 . The stigmatisation towards HIV/AIDS Index yielded a Cronbach alpha of .76 and the split-half reliability coefficient was .74 .

In addition open questions were asked about background characteristics of their sex work by the second and third author. The guiding questions included how sex work was started, the conditions of sex work, characteristics of clients, and attitudes towards sex work. 
Translation and backtranslation of the questionnaires were done from English into two of the major target languages of the study population (Northern Sotho and Tsonga). This was done according to scientifically established criteria and procedures.

\section{Analysis}

Using the SPSS version 11.0 the Pearson's product-moment correlation coefficients were calculated to evaluate relationships between subscales. The t-test was used for analysis of differences between means. Open-ended questions were content analyzed (Mostyn, 1985: 120-5).

\section{Results}

Results are presented into (1) quantitative and (2) qualitative results.

\section{(1) Quantitative results}

\section{Sample characteristics}

There were 70 sex workers, 29 from Phalaborwa and 41 from Tzaneen area in the Limpopo Province in South Africa. The mean age of the sex workers was 26.6 years $(S D=5.5$ years), ranging from 17 to 45 years. Eleven (15.7\%) had never attended school, $19(27.1 \%)$ had primary, $37(52.9 \%)$ had secondary, and three had tertiary $(4.3 \%)$ education. Half of the sex workers reported not to belong to any religion (35, 50\%), followed by Zion Christian church (14, 20\%), African or traditional religion $(11,15.7 \%)$ and others $(9$, $12.9 \%)$. Most belonged to the Northern Sotho $(33,47.1 \%)$ and Tsonga $(30,42.9 \%)$ ethnic group, and 7 others $(10 \%)$. Fifty $(71.4 \%)$ were not married and not living with a sex partner, $14(20 \%)$ were not married and living with a sex partner, 4 (5.7\%) were currently married and not living with the spouse, and $2(2.9 \%)$ were currently married and living with the spouse. The majority $(74 \%)$ of the participants indicated that they had lived in Phalaborwa or Tzaneen for at least the last 5 years. Half $(51.7 \%)$ of the commercial sex workers had only sold sex within the area of Phalaborwa or Tzaneen and not elsewhere, whereas the other group had sold sex in major cities in the province and a neighbouring province.

\section{Substance use}

From the sex workers $23(33.3 \%)$ reported that they drink alcohol everyday and $25(36.2 \%)$ at least once a week; seven $(10 \%)$ had used cannabis in the past, and two $(2.9 \%)$ had injected drugs.

\section{Sexual activity}

The mean age of first sex amongst sex workers was found to be 16.2 years $(S D=2.0)$ and the mean age of selling sex for the first time was 20.9 years ( $S D=4.5$ ), ranging from 17 to 45 years.

Eleven (15.7\%) were earning money from other work than sex work. The majority $(69 \%)$ was supporting the family- on average $2.8(\mathrm{SD}=1.4)$ persons- with sex work. Sex workers reported that the average number of paying sex clients in the last week were $4.2(\mathrm{SD}=4.2)$, ranging from 1 to 25 , and the mean number of non-paying clients were $0.3(S D=0.7)$ in the last week, ranging from 0 to 3 . The mean number of different sex partners was $4.1(\mathrm{SD}=3.4)$ in the last week.

Further, sex workers reported that the mean number of sex clients on their last day of sex work was $2.4(\mathrm{SD}=2.0)$. The mean amount of money received from the last paying or working day was $\mathrm{R} 233$ ( $\mathrm{SD}=170$ ), ranging from 20 to 800 Rand (1 US \$=9 Rand).

\section{HIV risk behaviour}

Ten (14.3\%) did not use a condom with their last paying client. Twenty-nine $(41.1 \%)$ reported that they would use a condom with a paying client every time, $33(47.1 \%)$ almost every time, $8(11.4 \%$ ) sometimes, and $2(2.9 \%)$ never. Reasons for not using a condom were partner objected, did not like them, used other contraceptives, and did not think it was necessary. One fifth ( $21.4 \%$ ) said they had non-paying clients, and the mean number of non-paying partners in the past 30 days was $2.8(\mathrm{SD}=1.3)$. Two-thirds did not use a condom with the last non-paying partner. Major reasons for not using a condom with a non-paying partner was partner objected, using other contraceptive and don't like them.

During the past 12 months, ten (14.3\%) participants indicated that their sexual partner(s) had forced them to have sex.

Using a student t-test it was found that condom use with a paying or non-paying partner was neither related with formal education ( $t=1.22$, not significant) nor with the HIV/ AIDS knowledge score $(t=1.02, \mathrm{~ns})$.

\section{Knowledge and availability of condoms}

Almost all had heard about male condoms before and knew where to obtain male condoms. The most known place for the participants to obtain male condoms was the clinic (93\%), followed by hospital (74\%), pharmacy (70\%), and bar/guest house/hotel (49\%). Almost half (46\%) indicated that they can obtain male condoms from friends and only one $(1.4 \%)$ mentioned the peer educator.

Most $(55,78.6 \%)$ reported that it takes them less than 10 minutes to obtain a male condom from their house or from where they work. Eight (11\%) had no condoms on-hand on them or in the room, $19(27 \%)$ had less than 5 condoms, and $43(61 \%)$ had 5 and more condoms.

\section{Female condoms}

The majority of the sex workers $(61,91 \%)$ had heard about a female condom but only $10(14 \%)$ had ever used a female condom, and about half $(47 \%)$ knew a place from which one could obtain a female condom. The most known place from where to obtain female condoms was the pharmacy, followed by the clinic, and hospital. Some (7\%) of the sex workers indicated that the female condom could be obtained from friends and none from peer educators.

\section{Sexually transmitted infections (STIs)}

Majority $(63,90 \%)$ of the respondents had heard about diseases that can be transmitted through sexual intercourse, while 7 (10\%) had not heard about STIs. Participants were 
further asked to describe any symptoms of STIs. Correct descriptions of STIs in women included, foul smelling discharge $(45,64 \%)$, genital discharge $(52,74 \%)$, burning pain on urination $(11,16 \%)$, genital ulcers/sores $(48,69 \%)$, itching $(11,16 \%)$, abdominal pains $(16,23 \%)$, swellings in groin area $(7,10 \%)$, and other $(33,47 \%)$.

Ten (14.3\%) of the participants indicated that they had genital discharge during the past 12 months and $9(12.3 \%)$ reported that they had a history of a genital ulcer/sore in the past 12 months.

The most important treatment agents for STIs were the government clinic or hospital, followed by the traditional healer, and taking medicine had at home. Most (63\%) sought treatment from the government clinic or hospital first for STI symptoms, followed by the traditional healer $(25 \%)$. Nobody seemed to have consulted the private clinic or hospital and private pharmacy first.

Most, did not tell their sexual partner about the discharge or STI, did not stop having sex when having the symptoms, and did not use a condom during the time they had symptoms. Most participants obtained their medicine for the last episode of symptoms of STI from a government clinic or hospital, followed by a traditional healer, and took medicine they had at home. The majority $(70 \%)$ of the women consulted a health worker within a week of first experiencing STI symptoms. All women reported that they took all the medicines prescribed.

\section{HIV/AIDS knowledge and stigma}

Almost all sex workers (97\%) said they had heard about HIV or the disease called AIDS. The majority (70\%) indicated that they know someone who is infected with HIV or who has died of AIDS.

An HIV/AIDS knowledge score was calculated by adding up 9 items (score range from 0 to 9). Participants had a mean HIV/AIDS knowledge score of 6.2 (range 0-9) ( $\mathrm{SD}=1.6)$ indicating an inadequate knowledge. For example, $38.5 \%$ believed that a person can get HIV from mosquito bites and $17 \%$ indicated that a person could get the HIV virus by sharing a meal with someone who is infected. Pearson's product-moment correlation showed that educational level was associated with the HIV/AIDS knowledge score $(r=.32$, $\mathrm{p}<.05$ ) but age was not associated with the HIV/AIDS knowledge score ( $r=-.12$, ns). The student $t$-test found that having received basic HIV/AIDS education was also positively related with the HIV/AIDS knowledge score $(t=2.75, \mathrm{p}<.01)$. Having received basic HIV education $(t=2.81, p<.01)$ but not HIV knowledge $(t=1.32$, ns) was related with condom use.

Stigma towards persons with HIV/AIDS was assessed by six items, which were added up to create a Stigmatization Towards HIV/AIDS Index (range from 0 to 6, the higher the score the less the stigmatization of people with HIV/AIDS). The total mean score in this sample was $4.8(S D=1.6)$ indicating a positive attitude towards persons with HIV/AIDS. Pearson correlation indicated that the HIV/AIDS knowledge score was not associated with the stigmatization in$\operatorname{dex}(r=21, \mathrm{~ns})$. However, having received basic HIV/AIDS education was related with a more positive attitude towards persons with HIV/AIDS $(\mathrm{t}=2.19, \mathrm{p}<.05)$.

\section{HIV antibody test}

Half $(53 \%)$ felt that it is but $47 \%$ felt it is not possible in their community to get a confidential test to find out if they are infected with HIV. Twenty-two (31.4\%) indicated that they had had an HIV test. Most (77\%) had an HIV test voluntarily. However, four (18\%) of those who had a test did not find out the result of the test.

\section{Receiving HIV/AIDS information}

The majority $(53,76 \%)$ indicated that they had received basic knowledge about HIV/AIDS. The major agents of receiving information about $\mathrm{HIV/AIDS}$ were in descending order of importance: radio $(46,65.7 \%)$, television $(35,50 \%)$, poster $(30,42.8 \%)$, and health worker $(20,28.6 \%)$. More than half of the participants $(39,55.7 \%)$ listened to the radio every day and likewise $(19,27.1 \%)$ watched television everyday, but $13(18.6 \%)$ said they had not listened to the radio and $21(30 \%)$ said they had not watched television in the last 4 weeks.

\section{(2) Qualitative results}

\section{Types of sex workers}

Sex workers can be categorised into two groups: (1) those who operate around beer halls and (2) those who operate in the streets. Both groups are further divided into part-time or casual and full-time sex workers.

\section{(1) Sex workers around beer halls}

Casual sex workers do it only when they need extra money. Most of them sell sex because their friends are doing so to get extra money. They are youngsters and never married, but some have been in cohabitation in the past. Most of them do not have children. They sell sex because of peer pressure. They hang around the beer hall to get their customers. They only go there when they know that either workers from the military, contractors or mines have received their salaries. They have a schedule for the whole month that they follow.

Full-time sex workers: Most of the sex workers in this group have fixed clients who are soldiers and truck drivers and they meet them near the beer hall where trucks park for the evening. Although they don't get much money, they can't withdraw from sex work because they have given up about getting other kinds of jobs.

\section{(2) Street sex workers}

Casual sex workers. They sell sex only when they need money. They walk around the streets in the center of the town. Especially in areas where truck drivers park for a rest at night as well as around horse racing betting vendours. Most of them are young and have dropped out of school. They do not have someone to support with the money acquired from sex work. Only few have children and their parents help them to support their children. They spend the money from sex work on their own clothing and other personal needs. Few of them were once married, but were abandoned by their husbands and they have to look after the children by themselves. They accept money as little as 
R20-R50 for a sex on the spot and as much as R100-R200 for overnight sex. Some of them have no fixed customers; they accept anyone who comes to buy sex. Some have a steady sex partner who does not know that they are sex workers, and only few said that their partners knew that they were sex workers and that they accepted it because they were not working too.

Full-time sex workers do their work on daily basis along the street side that enters into the centre of town. They normally start working between $19 \mathrm{~h} 00$ and $20 \mathrm{~h} 00$ until late or until the morning of the following day. Most of them who sell sex in the streets said that they are desperate and do not have a source of financial and emotional support. Some had parental responsibility as single parents. They pay for their children's school fees, clothes and all household needs.

Most of them were married in the past, but separated from their husbands and had to sustain their households and the children. Few aged forty and above reported that they tried to seek for jobs but failed because they are overage. One said she is a domestic worker, but was not satisfied with her income. She does sex work to supplement her income from her work. Most said that they only targeted the white men as they pay them satisfactorily, from R50-00 to R350-400 depending on how long they spend doing sex. They said black men do not pay much and do not want to use a condom.

\section{Attitudes about sex work}

They acknowledged that selling sex was not a good thing and that they felt compelled to do so because they wanted to live better life. Further, they reported that selling sex was a last resort to them, having created work for themselves because of high rate of unemployment. Examples are:

"I am not proud of what I am doing, if I can get any kind of a job I will quit from the streets. As long as I can support my family."

"My husband is in prison. Although I returned to my parent's home, I am helping my parents to take care of the children by the money from sex work."

They are aware of HIV/AIDS and they use condoms regularly to prevent HIV/AIDS and other sexually transmitted infections. They do not mind what other people say when they see them hanging in the street wearing a short skirt to attract men who are sex hungry. Some people in the community know that they are selling sex and they accept them because they understand their situation. In their view this is the only simple and accessible means of generating money to support their families. Some other ladies are working as domestic workers in the town and also sell sex. The reason for that is that the money they earn from that work is insufficient to cover all things required in their household. So they decided to establish a simple job of walking around the street during the night, selling sex.

They reported that they realised that selling sex would help them to make extra income that can fully sustain their households. They reported that their children are enjoying life, because they afford to get everything they need. They also reported that God would forgive them for their living, while they knew that they were 'THE WORST SINNERS' in front of HIM (Re ile go ya diheleng ka 'tšatši la katlholo). They mentioned that to do sex work is a very risky behaviour because there was one case where a white man killed four sex workers in one night in the area. Some sex workers work in groups and with members of a particular group to support each other. Sometimes these groups tend to fight for territorial space and clients.

A member of one group reported that there was another member who had a policeman friend telling the policeman to arrest all members of the other group. They were arrested while the members of the other group were watching. They stayed in jail for about two days. The magistrate released them without any charges.

\section{Case examples Case 1}

One sex worker complained about the loss of both parents and that she is the mother of two. She said that she is from a disadvantageous family and never attended school since her parents died while she was still young. She is making money for her children's future, providing everything that the children need.

\section{Case 2}

The lady of 27 years of age reported that the reason of being a sex worker was because of shortage of jobs and her responsibility to take care and support her kid. No one of her family members was prepared to help her. Now she is busy making money by selling sex, and she is enjoying as she protects herself from unwanted pregnancy and HIV/ AIDS by using condoms. She said that she preferred white men, as they don't give problem on condom use, while on the other hand they pay without worries. So for black men, they are troubling as they deny using condoms by the notion that they can't eat sweets while it is inside the paper. Her ambition is to find a suitable job and leave prostitution.

\section{Case 3}

One lady had two children and she was pregnant and selling sex. She is smoking and also drinks alcohol. She said that she cannot stop selling sex because she is pregnant, that's her only way to get money so that she survives together with her children. She smokes and drinks alcohol so that she does not think too much and feels cool at night when she walks in the streets.

\section{Case 4}

One young lady reported that her husband is in prison. Although she returned to her parent's home, she is helping her parents to take care of her children from the money from sex work. After her partner's imprisonment, it is when she started to do sex work.

She reported that when her husband is released from prison she is going to stop sex work, and she makes sure that she hides what she was doing. According to her, sex work is boring because some white men clients enjoy oral sex, as they are not preferring to use condoms. 


\section{Case 5}

One reported that she is the only girl among boys, so she just had to do sex work because she is tired of household work, and her friend convinced her to do sex work by showing her the money she gets from doing sex work.

\section{Case 6}

Two young women reported that they were once married, have children and siblings that demand too much, while on the other hand their parents have past away, and their siblings are not accepting that their parents died. As there is a shortage of employment, they are forced by the situation to go for sex work. Although they realize that sex work gives them more money than another job, so they are no longer looking for another job than sex work. The money from sex work is double the amount of those who have ordinary work.

\section{Discussion}

The study found among semi-urban South African female sex workers an inadequate knowledge of HIV prevention methods and some incorrect beliefs about AIDS transmission. Most sex workers reported condom use with their last sex client, inconsistent condom use with paying partners, had poor condom use with regular partners, one third were drinking alcohol daily, one quarter had had voluntary HIV tests, and three quarters had been exposed to HIV interventions.

The mean number of sex clients on the last day of sex work was 2.4 in this study. In Johannesburg most commercial sex workers (88\%) saw five or fewer clients on a working day (Rees et al., 2000: 283), in Durban on average, sex workers had just under three clients a day (Varga: 2001: 355), and in Bulawayo in Zimbabwe the average was 1.3 clients a night (Wilson, Sibanda, Mboyi, Msimanga \& Dube, 1990: 609). This study found that $14.3 \%$ did not use a condom with their last paying client, $58.9 \%$ would not always use a condom with a paying client, and two-thirds did not use a condom with the last non-paying partner. Among female sex workers in urban centres in Cameroon $45.1 \%$ reported to have used a condom with the last client and $20.7 \%$ with the last nonclient (Weir, Roddy, Zekeng, Ryan \& Wong, 1998: 297). Varga and Blose (1996: 9) found among sex workers in Durban that only $22 \%$ described themselves as "always" and $78 \%$ as "usually" using condoms with clients. $44 \%$ of sex workers in Harare in 1989 reported using a condom in their last paid sex act (Wilson, Chiroro, Lavelle \& Mutero, 1989: 269). Varga (2001: 358) also found among commercial sex workers in Durban that sex partners were grouped into personal and professional or casual. The former was viewed as "clean" and "safe", trustworthy, emotionally intimate and loving. The latter was the antithesis in being considered "dirty" and "unsafe", unknown, untrustworthy and emotionally sterile. The primary distinctions between these two categories were the motivation behind the sex act (personal emotional versus professional financial) and whether condom use (i.e. protection from HIV and STI infection) was deemed necessary. HIV infection risk from the former was viewed as negligible or non-existent, whereas risk from the latter was deemed considerable.

Further, $14.3 \%$ in this study reported to have been raped in the past 12 months. Among sex workers on Benin City, Nigeria, $40 \%$ reported that they had ever been raped (Asowa-Omorodion, 2000: 341).

In this study, major reasons for not using a condom with a paying client were partner objected, did not like them, used other contraceptives, and did not think it was necessary. In addition, one-third said that they drink alcohol daily, which may impair their ability to successsfully negotiate condom use. Varga and Blose (1996: 9) identified dire financial straits, client's appearance clean, trustworthy threat of physical violence, and high alcohol consumption as obstacles to consistent condom use among sex workers in Durban.

Having received basic HIV/AIDS education but not HIV knowledge was in this study related with condom use. Varga (1997: 74) also found among commercial sex workers in Durban that HIV/AIDS awareness had minimal impact on condom use. Many studies have emphasized the lack of correlation between sexual knowledge and sexual behaviour (e.g. Wojcicki \& Malala, 2001: 100). However, HIV/AIDS education still seem important to increase condom use among these sex workers.

One-third of the study participants indicated that they had had an HIV test. However, four (18\%) of those who had a test did not find out the result of the test. Wojcicki and Malala (2001: 115) found among sex workers in Johannesburg that they do not want to know their HIV status because they fear depression, having to change their lives (leave the sex industry) and perhaps the threat of HIV would only contribute to their already high levels of stress and difficulties.

Among the sex workers in this study the most important treatment agents for STIs were the government clinic or hospital, followed by the traditional healer, and taking medicine had at home. The role of traditional healers in the treatment of STIs has also been noted among commercial sex workers in Morogoro township in Tanzania (Outwater et al., 2001: 19) and in Benin City in Nigeria (Asowa-Omorodion, 2000: 342), and need to be considered in STI treatment programmes for sex workers.

This study found a lack of cohesion among the sex workers which was also found among commercial sex workers in Bulawayo in Zimbabwe (Wilson et al., 1990: 609).

The majority of the sex workers in this study had heard about a female condom and $14 \%$ had ever used a female condom. Marseille, Kahn, Bellinghurst and Saba (2001) concluded that a well-designed female condom programme oriented to commercial sex workers and other women with casual partners is likely to be highly cost-effective and can save public sector health funds in rural South Africa. Ray, Van De Wijgert, Mason, Ndowa and Maposphere (2001: 581 ) investigated the constraints faced by sex workers in the use of female and male condoms for safer sex in urban Zimbabwe.

Questionnaire data indicated high self-reported acceptability of female condoms, but focus group discussions revealed that a main obstacle to female condom use was client distrust of unfamiliar methods. 


\section{Conclusion}

The distinction between regular and casual partners is important and based on the nature and extent of financial support. It is also related to condom use and therefore to risk.

The message that condoms should be used consistently during high-risk behaviour needs to be reinforced, and the definition of a high-risk relationship needs to be extended from casual partnerships to include multiple regular partnerships.

A lack of cohesion among the commercial sex workers should be addressed by fostering organized and motivated groups for health education. Focused peer-mediated educational programmes among female sex workers is urgently needed to reduce sexually transmitted infections and human immunodeficiency virus transmission in the studied semi-urban South African areas targeting sex workers around beer halls and street sex workers.

Recommendations to reduce the sex workers' risk for HIV infection include negotiation and communication skills to enable them to persuade their clients to use condoms, development of strategies through which they can maximally use their group strength to facilitate unified action, and accessibility of protective methods they can use and control. The role of alcohol as an impediment to health interventions and the feasibility of using bar security and the bar personnel as health educators for sex workers operating around beer halls is recommended.

It is equally important to direct health interventions at clients, many of whom are resistant to condom use. In addition, men and women's empowerment through education, business, and equal rights needs to be addressed at all levels of society. (Karim, Karim, Soldan \& Zondi, 1995: 1485; Ngugi, Wilson, Sebstad, Plummer \& Moses, 1996: 240).

\section{Acknowledgements}

The financial assistance the Palaborwa Foundation and the National Research Foundation (South Africa) towards this research is hereby acknowledged. Opinions expressed in this publication and conclusions arrived at, are those of the authors and are not necessarily to be attributed to the National Research Foundation.

\section{References}

ABDOOL KARIM, Q \& ABDOOL-KARIM, S 2000: Epidemiology of HIV in South Africa. Internet Publication (www.healthnet.org.za). last update: 13 April 2000, Durban: South African Medical Research Council, 1-5.

ASOWA-OMORODION, FI 2000: Sexual and health behaviour of commercial sex workers in Benin City, Edo State, Nigeria. Health Care for Women International. 21(4): 33545 .

FAMILY HEALTH INTERNATIONAL 2000. Behavioural surveillance surveys: guidelines for repeated behavioural surveys in populations at risk of HIV. www.fhi.org.
GYSELS, M; POOL, R \& NNALUSIBA, B 2002: Women who sell sex in a Ugandan trading town: life histories, survival strategies and risk. Social Science \& Medicine. 54(2): 179-92.

KARIM, QA; KARIM,SS; SOLDAN, K \& ZONDI, M 1995 : Reducing the risk of HIV infection among South African sex workers: socioeconomic and gender barriers. American Journal of Public Health. 85(11): 1521-5 Comment in: American Journal of Public Health. 85(11):1485-8.

LEGGETT, T. 2002: Drugs, sex work, and HIV in three South African cities. Societv in Transition. 32(1): 101-109.

MARSEILLE, E; KAHN,JG; BILLINGHURST, K\&SABA, J 2001: Cost-effectiveness of the female condom in preventing HIV and STIs in commercial sex workers in rural South Africa. Social Science \& Medicine. 52(1): 135-48.

MOSTYN, B. 1985: The content analysis of qualitative research data: a dynamic approach. (In: M Bressner, J. Brown, \& D Conta (Eds.) The research interview: uses and approaches pp. 115-145. Orlando, FL: Academic Press).

MZAIDUME, Z; CAMPBELL, C \& WLLIAMS, B 2000: Community-led HIV prevention by southern African sex workers. Research for Sex Work. 3: 23-29.

\section{NGUGI, EN; WLSON, D; SEBSTAD, J; PLUMMER, FA \& MOSES, $S$ 1996:}

Focused peer-mediated educational programs among female sex workers to reduce sexually transmitted disease and human immunodeficiency virus transmission in Kenya and Zimbabwe. Journal of Infectious Diseases. 174 Suppl 2:240-7.

OUTWATER, A; NKYA, L; LWHHULA, G; O'CONNOR, P; LESHABARI, M; NGUMA, J; MWIZARUBI, B; LAUKAMM-JOSTEN, U; GREEN, EC \& HASSIG,SE 2000: Patterns of partnership and condom use in two communities of female sex workers in Tanzania. Journal of Assoc Nurses AIDS Care. 11(4): 46-54.

OUTWATER, A; NKYA, L; LYAMUYA, E; LWIHULA, G; GREEN, EC; HOGLE, J; HASSIG, SE \& DALLABETTA, G 2001: Health care seeking behaviour for sexually transmitted diseases among commercial sex workers in Morogoro, Tanzania. Culture. Health \& Sexuality. 3(1): 19-33.

PICKERING, H; QUIGLEY, M; HAYES, RJ; TODD, J \& WILKINS, A 1993:

Determinants of condom use in 24,000 prostitute/client contacts in The Gambia. AID,S 7(8): 1093-8.

PICKERING, H; OKONGO, M; NNALUSIBA, B; BWANIKA, K \& WHITWORTH, J 1997: Sexual networks in Uganda: casual and commercial sex in a trading town. AIDS Care. 9(2): 199-207.

RAY,S; VAN DE WIJGERT, J; MASON,P; NDOWA, F \& MAPOSPHERE, C 2001: Constraints faced by sex work- 
ers in use of female and male condoms for safer sex in urban Zimbabwe. Journal of Urban Health. 78(4): 581-92.

REES, H; BEKSINSKA, ME; DICKSON-TETTEH, K; BALLARD, RC \& HTUN, YE 2000: Commercial sex workers in Johannesburg: risk behaviour and HIV status. South African Journal of Science. 96: 283-184.

VARGA, CA 1997: The condom conundrum: barriers to condom use among commercial sex workers in Durban, South Africa. African Journal of Reproductive Health. 1(1): $74-88$.

VARGA, CA 2001: Coping with HIV/AIDS in Durban's commercial sex industry. AIDS CARE. 13(3): 351-365.

VARGA, CA \& BLOSE, FN 1996: The symbolism and dynamics of condom use among commercial sex workers in Durban, South Africa. African Anthropology. 3(2): 2-18.

WEIR, SS; RODDY, RE; ZEKENG, L; RYAN, KA \& WONG, EL 1998: Measuring condom use: asking "dod you or don't you" isn't enough. AIDS Education and Prevention. 10(4): 293-302.

WILSON, D; CHIRORO,P; LAVELLE,S \& MUTERO,C 1989: Sex worker, client sex behaviour and condom use in Harare, Zimbabwe. AIDS Care. 1(3): 269-80.

WILSON, D; SIBANDA, B, MBOYI.L; MSIMANGA,S \& DUBE, G 1990: A pilot study for an HIV prevention programme among commercial sex workers in Bulawayo, Zimbabwe. Pleasant. Social Science \& Medicine. 31(5): 609-18.

WOJCICKI, JM \& MALALA, J 2001: Condom use, power and HIV/AIDS risk: sex-workers bargain for survival in Hillbrow/Joubert Park/Berea, Johannesburg. Social Science \& Medicine. 53(1): 99-121. 